\title{
A FORÇA DA PALAVRA EM NICOLAU DE CUSA
}

\author{
Power of the Word and According to Nicholas of Cusa \\ La Fuerza de la Palabra en Nicolás De Cusa
}

SONIA LYRA

\begin{abstract}
Resumo: A partir do momento em que se transpõe a dialética dos símbolos, rumo à experiência mística, é a força da palavra devidamente potencializada o que vai poder mover o ouvinte, uma vez que há uma força oculta por detrás de cada palavra. A força das palavras aparece, como uma contracção da força da mente, que se 'explica' nas múltiplas palavras que são, no mais fundo delas próprias, núcleos energéticos discursivos e que só podem ser entendidas nesse jogo dinâmico que se estabelece entre as coisas do mundo externo e seu referente interno, isto é, a mente. O discernimento é passado inicialmente, como propõe Nicolau de Cusa, por imagens sensíveis, continuando a proposta de Jesus, que falou inicialmente por figuras, mas disse também que chegaria a hora em que já não falaria por figuras, mas claramente, pois as palavras que de Deus recebeu, ele as deu aos homens cumprindo-se a profecia: no princípio era o Verbo (In principio erat verbum), no qual subjaz o poder criador da palavra. A proposta do Cusano é que nesta teoria do conhecimento se reconheçam as limitações da palavra e do discurso, inscrevendo-se a sua dialética no conhecimento intelectual da trindade, o qual, na unidade, ultrapassa tudo. Palavras-chave: Nicolau de Cusa; Força da palavra; Dialética; Verbo.
\end{abstract}

Resumen: A partir del momento en que se transpone la dialéctica de los símbolos rumbo a la experiência mística, es la fuerza de la palabra debidamente potencializada, lo que hará hacer estremecer al oyente, una vez que hay una fuerza oculta detrás de cada palabra. La fuerza de las palabras aparece como una contracción de la fueza mental, que se 'explica' en las múltiples palabras que son en lo más fondo de las mismas, núcleos energéticos discursivos y que solo pueden ser compreendidas en ese juego dinámico, que se estabelece entre las cosas del mundo externo y su referente interno, esto es, la mente. El discernimiento es pasado inicialmente como lo propone Nicolás de Cusa, por imágenes sensibles, dándole continuidad a la propuesta de Jesús; que habla inicialmente por figuras, pero también disse que llegaría la hora en que no hablaría mas por médio de figuras, pero claramente, pues las palabras que de Dios recibió, él se las dio a los hombres cumpliendo la profecia: En el pincipio era el verbo (In principio erat verbum) en el cual subyace el poder crador de la palabra. La propuesta del Cusano es que en esta teoria de conocimiento sean reconocidas las de limitaciones de la palabra y del discurso, inscribiéndose en su propia dialéctica, en el conocimiento intelectual de la Trinidad, lo cual en la unidad lo ultra passa todo.

Palabras-clave: Nicolás de Cusa; Fuerza de la palabra; Dialéctica; Verbo.

\begin{abstract}
From the moment in which the dialectics of symbols is transposed, toward the mystical experience, it is the power of the word duly potentialized that will move the listener, once there is a hidden force behind each word. The power of the words appears as a contraction of the strength of the mind that "explains" itself in multiple words that are, in their deeper selves, discoursive energetic cores and that can only be understood in this dynamic game that is established between the things of the external world and its internal referent, that is, the mind. Discernment is passed initially, as Nicholas of Cusa proposed, by sensitive images, continuing Jesus' proposal that spoke at the beginning through images, however He also said that the time would come when He would no longer speak through images, but clearly, for the words He received from God He[[he gave them to men, thus fulfilling the prophecy: in the beginning was the Word (In principio erat verbum), in which lies the creative power of the word. Nicholas of Cusa's proposal is that in this theory of knowledge the limitations of the word and of the discourse are acknowledged, registering its dialectics in the intellectual knowledge of Trinity which, in the unity, exceeds all.
\end{abstract}

Keywords: Nicholas of Cusa; Power of the Word; Dialectics; the Word.

\section{Introdução}

Um jornalista perguntou a Madre Tereza de Calcutá: "Quando você reza, o que você diz a Deus?" E ela respondeu: "Não falo, escuto." O jornalista então perguntou: "O que Deus diz a você??" Madre Tereza respondeu: "Ele não fala. Ele escuta. E se você não pode compreender isso, não posso lhe explicar." A epígrafe de meu livro: Nicolau de Cusa: Visão de Deus e Teoria do Conhecimento (Lyra, 2012) aponta para essa "estranha" linguagem. Ela diz:
"Não só de pão vive o homem, mas de toda palavra proferida pela boca de Deus." Essa frase precisa ser entendida também no modo desse diálogo, assim como está exposto por Madre Tereza para que nela se possa intuir a força da palavra.

Sem a força da paixão presente na palavra, esta é apenas conceito, mas um conceito daquilo que já se conhece, ou assim se pensa conhecer, como esquematização lógico-categorial ou conjectural que desemboca na assim chamada ciência positiva. 
Jesus Cristo é o logos que, segundo ele mesmo, é "o pão da vida" (Jo 6,35), o pão que, quem comer "viverá eternamente" (Jo 6,51). Este pão não é como aquele que os pais comeram e pereceram, mas o pão da palavra. O mesmo Cristo ainda disse: "Por que não reconheceis minha linguagem? É porque não podeis escutar minha palavra" (Jo 8,43), e completa dizendo que "quem é de Deus ouve as palavras de Deus" (Jo 8,47). Destas passagens, segue-se o porquê da vinda da palavra, pois disse ainda Jesus: "para um discernimento é que vim a este mundo" (Jo 9,39). O discernimento é passado inicialmente, como propõe Nicolau de Cusa por imagens sensíveis. Continuando a proposta de Jesus: "Disse-vos essas coisas por figuras. Chega a hora em que já não vos falarei em figuras, mas claramente vos falarei do Pai" (Jo 16,25). É quando Jesus diz aos discípulos que a vida eterna está em que conheçam "o único Deus verdadeiro" (Jo 17,3), pois as palavras que de Deus recebeu ele as deu aos homens cumprindo-se a profecia: no princípio era o Verbo (In principio erat verbum) (André, 2006, p. 8), no qual subjaz o poder criador da palavra. A proposta do Cusano é que nesta teoria do conhecimento se reconheçam as limitações da palavra e do discurso, inscrevendo-se a sua dialética no conhecimento intelectual da trindade, o qual, na unidade, ultrapassa tudo.

O Verbo divino, ao se plurificar nas suas expressões, que são o mundo das criaturas, em seus sinais e palavras sensíveis, é confirmado por Nicolau de Cusa quando ele afirma:

De acordo com esta comparação, o nosso princípio unitrino, pela sua bondade, criou o mundo sensível como matéria e uma espécie de voz, na qual fez resplandecer de modo vário o verbo mental, a fim de que todas as coisas sensíveis sejam o discurso de várias elocuções do Deus Pai, explicadas através do Verbo, seu Filho, tendo como fim o espírito dos universos, para que a doutrina do sumo magistério transborde, através dos sinais sensíveis, para as mentes humanas e as transforme perfeitamente num magistério semelhante, de modo a que todo o mundo sensível esteja em função do intelectual, o homem seja o fim das criaturas sensíveis e Deus glorioso seja o princípio, o meio e o fim de toda a sua actividade (André, 2006, p. 9).

Segundo André (2006), no De filiatione Dei, o Cardeal aponta o uno como o pai ou o gerador do Verbo, querendo dizer com isto que "tudo aquilo que é dito em qualquer palavra, significado em qualquer sinal e assim sucessivamente" (André, 2006, p. 9), exprime em forma de palavra humana o verbo divino, sendo que na sua força se fundamentam a força da palavra do homem e, simultaneamente, os seus limites. "A sua força, porque ela é a expressão do verbo divino, os seus limites, porque é sempre uma expressão contraída e limitada pela finitude hu- mana que dista infinitamente de plenitude de sentido da infinitude divina” (André, 2006, p. 9).

Independente da possibilidade de morrer, devido à sua natureza mortal, pode o homem chegar à experiência da vida do espírito imortal em virtude do Verbo Encarnado no homem Jesus Cristo, "in virtute verbi dei" (André, 2006, p. 10). Nele a humanidade é o nexo de ligação entre a natureza inferior e a superior, isto é, da temporal e da eterna, e que se experimenta, em semelhança, pela fé e pelo amor. É quando a sabedoria encarnada revela, com o seu exemplo, o caminho para a vida, pelo qual ainda que se morra se experimenta a ressurreição da vida, "que é tudo o que se busca" (Vescovini, 1998, p. 132).

Tudo o que se busca, filosoficamente, é considerar a força da palavra quase como se o nome fosse a representação precisa da coisa. Mas, se os nomes foram impostos às coisas segundo a razão concebida pelo homem, então os nomes não são precisos, pois uma coisa pode ser denominada com outros nomes talvez mais precisos. É por isso que os desacordos não estão na razão que dá substância às coisas, mas nos vocábulos que são atribuídos diferentemente às diversas razões das coisas. É em virtude da virtus ou força da palavra, cujo conceito coincide com sapientia, que se transfere o verbo divino para os verbos humanos, sendo estes então "explicationes da sapientia na sua unidade mais profunda e absoluta" (André, 2006, p. 10).

Nicolau de Cusa desenvolve essa "dinâmica expressiva e manifestativa das palavras” (André, 2006, p. 13) em várias de suas obras, entre elas no De pace fidei; De principio; De mente e Compendium. O Cusano, da mesma forma que Agostinho, afirma que a palavra que soa exteriormente

é um sinal da palavra que brilha no interior, à qual melhor convém o nome de verbo. Na verdade, a palavra que os lábios pronunciam é a voz do verbo e chama-se também verbo porque aquele a assume para que apareça exteriormente (André, 2006, p. 12).

Como falar é manifestar, o Cardeal quer traduzir em teoria a palavra interior que, por si mesma, já é uma tradução no "nome preciso e indizível" (André, 2006, p. 13), do qual a linguagem humana é a explicatio.

Da mesma forma, Platão diz que " $a$ verdade é anterior aos vocábulos, aos discursos, ou seja, às definições dos vocábulos e às imagens sensíveis, e ele traz como exemplo, o desenho do círculo, do seu nome, da sua definição verbal e do seu conceito" (Vescovini, 1998, p. 133), ainda que Dionísio Areopagita recomende que se dê "mais atenção à intenção que à força da palavra" (Vescovini, 1998, p. 134). De qualquer modo, para Nicolau de Cusa, tudo que pode ser dito é o verbo, é a manifestação de um verbo único, que se constitui na arte da fala, "uma arte infinita, não no seu resultado, mas no seu processo e no seu dinamismo" (André, 2006, p. 13), quando então 
a sua limitação a transforma na busca pela palavra infinita, que, oculta no silêncio de sua plenitude, é a fonte de todas as palavras. No entanto, no segundo capítulo do De docta ignorantia, o Cusano chama a atenção num esclarecimento preliminar para o fato de que, aquele que quer atingir o sentido do que está para ser dito deve elevar o intelecto "para lá da força das palavras, mais do que insistir nas propriedades dos vocábulos que não podem adaptar-se convenientemente a tão elevados mistérios intelectuais" (Cusa, 2003). Os exemplos dados, ele os utilizará como guias para a elevação do plano das coisas sensíveis para o intelectual.

O uso das matemáticas, por exemplo, tem como finalidade confrontar as etapas metodológicas necessárias, partindo de uma lógica conjectural, edificada, segundo André, "sobre o princípio de não-contradição" (André, 2001, p. 321); seguindo para uma dialética coincidencial, edificada "sobre o princípio da coincidência dos opostos" (André, 2001, p. 321) e finalmente desembocando numa dialógica transsumptiva, edificada "sobre a consciência da distância, mas também sobre a natureza dialógica do movimento pelo qual nos sentimos chamados a transpor essa distância" (André, 2001, p. 321), reflexão esta que conduz para a experiência do infinito em que já não há figuras.

Uma vez que se pode considerar a questão sobre a nomeação de Deus ou de se saber o que Deus é e como é possível experimentá-lo como o centro ou o princípio da coincidência, como o lugar a partir do qual se pode compreender toda a filosofia de Nicolau de Cusa, pode-se também deduzir que essa teoria do conhecimento proposta pelo Cusano surge na introdução do De docta ignorantia como "uma hermenêutica dos nomes divinos, profundamente influenciada pela obra do Pseudo-Dionísio, como já foi referido, e que só terminará com a última obra, o De ápice theoriae" (Cusa, 2003, p. XXI).

No ápice da teoria, experiência (afeto, humor) e método (compreensão da realidade), próprios da dinâmica de realização da realidade, co-incidem numa transsumptio cusana, que, para Fogel (2003), "se constitui num pôr-se no mesmo tônus, no mesmo "tom", ou seja, na mesma experiência, na mesma origem; trata-se assim de um sintonizar-se, de um sincronizar-se com a "coisa" - assim se é co-originário e co-partícipe” (Fogel, 2003, p. 49). O conhecimento torna-se então simpatia, paixão. É a experiência do logos, o sentido e a força da palavra nela contida e por ela perpassada.

É o momento em que a força da palavra se torna conhecimento, em que o problema do conhecimento e da palavra é o mesmo que o problema do real. "É nessa hora, nesse contexto de intensidade máxima do pensamento, nessa hora de radical concretização da essência do homem, que é preciso ouvir aquela afirmação: viver, existir, ser homem, no modo mais radical ou essencial possivel, é conhecer" (Fogel, 2003, p. 52). É transpor-se para este ou aquele humor "o necessário da ocasião, $d a$ 'hora' - para então ajustar-se, 'adequar-se' com ele, isto é, com as coisas" (Fogel, 2003, p. 53). Vê-se então que ser simpático é ajustar-se, supondo-se que verdade seja mesmo a adequação, a correspondência, a consonância com as coisas.

No entanto, segundo Vescovini, na obra La Caccia della sapienza (1998), o Cusano afirma que ninguém esteve mais atento a essa questão do que Aristóteles, para quem "aquele que forjou todos os nomes sabia perfeitamente ter expresso isto que sabe nos seus nomes e, como desenvolver esta ciência, fosse encontrar a perfeição do saber" (Vescovini, 1998, p. 134). Mas, apesar de tudo isto, chega o momento em que o buscador da sabedoria precisa negar todos os nomes que o homem impôs a Deus. Negar os nomes é diferente de interpretá-los. A interpretação requer alguns princípios; assim como fez Nicolau de Cusa em De genesi, ao partir da idéia de que todos os que falaram da Gênese fizeram-no de modos diversos. Usando o tema da Gênese como base a interpretação aponta inicialmente para "a necessidade de contextualizar o discurso bíblico na capacidade humana de compreensão e de apreensão" (Vescovini, 1998, p. 322); em seguida aponta para "a transformação do movimento interpretativo num movimento de assimilação ao idem, ou seja, de confluência para o idem indizível, por um processo de relativização das formas contraídas da expressão humana" (Vescovini, 1998, p. 322), e finalmente entendendo que "a percepção de que as interpretações dos sábios e Padres da Igreja não são senão modos diversos de apreensão do idem absoluto" (Vescovini, 1998, p. 322), que cada qual procura representar de modo assimilativo.

É desse modo que a interpretação dos textos bíblicos, filosóficos, teológicos ou místicos, funciona igualmente para todos, segundo esses princípios. Mesmo as expressões religiosas, ainda que permeadas "pela força da sabedoria inefável” (Vescovini, 1998, p. 325), não sejam senão conjecturas. Presente já no De intellectu et intelligibili de Alberto Magno', está a afirmação de que "o intelecto é o ponto para o qual tendem todas as filosofias" (Vescovini, 1998, p. 134). É onde, para o teólogo Alberto, se articulam a natureza do pensar com a natureza da graça, apontando para uma visão beatífica do intelecto divino que é a partir de onde falam todos os filósofos, isto é, de uma teofania - manifestação ou revelação de Deus.

Na medida em que, para Alberto, as figuras do filósofo e do profeta tendem a se sobrepor, esse homem pode se elevar pelo pensamento ao "intelectus divinus" (Vescovini, 1998, p. 308). Citando Avicena, Hermes e Homero, Alberto continua dizendo ousadamente que o filósofo é nexus dei et mundi, tendo uma função na liturgia cósmica. Instrumento de uma espécie de palingenesia ${ }^{2}$,

\footnotetext{
Cf. A. Combes, Jean Gerson commentateur dionysien. Texte inédit. Démonstration de son authenticité. Appendices historiques, Paris, Vrin, 1940. [1973].

2 Renascimento, regeneração. Fil. Rel. O mesmo que metempsicose. Fil. Entre os estoicos, retorno periódico e incessante dos mesmos fenômenos; eterno retorno. Aulete Digital.
} 
o filósofo aparece em Scotus Erigena e Mestre Eckhart numa imensa lista de citações, operando como que uma fusão da "abstractio filosófica e da ablatio místico-teológica” (Vescovini, 1998, p. 312). Naturalmente surgem críticos, como Gerson, que preferem a visão de Agostinho, Dionísio e São Boaventura, que, a seus olhos, por não serem filósofos, têm mais direito de falar da ablatio por serem cristãos. O conteúdo de toda essa busca filosófico-teológica e mística é definido por al-Farabi como "a união do filósofo com o intelecto absoluto [séparés]” (Vescovini, 1998, p. 329), em outras palavras, como uma via que se adquire, objeto de um trabalho que se supõe seja progressivo. Mestre Eckhart denominou esse homem da busca de "homem nobre", "homem pobre" ou "homem desapegado" (Vescovini, 1998, p. 330). Discípulo de Alberto, Eckhart "continuou em teologia a obra compilada por seu mestre na filosofia” (Vescovini, 1998, p. 333).

O modelo do homem desprendido (l’home détaché) é Jesus Cristo, que na exegese de Lucas $(19,12)$ aparece como um homem de nobre origem que parte para uma região distante a fim de ser investido da realeza e então voltar. Essa metáfora aponta para a necessidade de superação, de "ultrapassamento do saber em direção ao Verbo" (Vescovini, 1998, p. 336), quando então o modelo da vida bem-aventurada é cristológico. Encontrar esse fundo sem imagens, onde a ética e a filosofia estão para lá de todos os nomes de Deus, é a verdadeira pobreza, é quando filosofar e contemplar

consiste em "reentrar" em seu próprio fundo e, estando lá, "agir" "sem porque”, "nem por Deus, nem por sua própria felicidade, nem por quem esteja fora de si, mas unicamente em consideração disto que é em si seu ser próprio e sua própria vida (Vescovini, 1998, p. 341).

No fundo, afirma De Libera, "Eckhart não diz nada além do que disse Orígenes: toda a filosofia já está na Escritura" (Vescovini, 1998, p. 350), especialmente no Novo Testamento, mais especialmente ainda, no Evangelho segundo São João.

A partir do momento em que se transpõe a dialética dos símbolos, rumo à experiência mística, é a força da palavra devidamente potencializada o que vai poder mover o ouvinte, uma vez que há uma força oculta por detrás de cada palavra. A força das palavras aparece, diz André: "Assim como uma contracção da força da mente, que se 'explica' nas múltiplas palavras que são, no mais fundo delas próprias, núcleos energéticos discursivos e que só podem ser entendidas nesse jogo dinâmico" (André, 2006, p. 18), que se estabelece entre as coisas do mundo externo e seu referente interno, isto é, a mente.

É assim que em seu desdobramento, o Verbo, Jesus Cristo, "não sendo cognoscível neste mundo onde, no âmbito da razão, da opinião, da doutrina, somos conduzidos, através de símbolos, pelas coisas desconhecidas ao des- conhecido, só é apreendido onde cessam as persuasões e começa a fé" (Cusa, 2003, p. 173). Uma vez que o conhecimento intelectual é dirigido pela fé, visto ser uma explicatio da fé, onde a fé não for sã, aí também não é possível um conhecimento intelectual verdadeiro, conduzindo nesse caso à debilidade dos princípios e fundamentos. Esta fé é o próprio Jesus Cristo, uma vez que como diz São João, é a própria encarnação do Verbo, a douta ignorância. E o Cusano finaliza dizendo que, "quando nos esforçamos por olhar com os olhos intelectuais, caímos na escuridão, sabendo que dentro dessa escuridão está o monte no qual só é permitido habitar àqueles que são dotados de intelecto" (Cusa, 2003, p. 173). São estes os capazes de compreender incompreensivelmente que "toda palavra corporal é sinal do verbo mental” (Cusa, 2003, p. 174) e que todas as coisas criadas são, da mesma forma, "sinais do Verbo de Deus" (Cusa, 2003, p. 174).

Esse conhecimento se manifesta gradualmente através da fé, pela qual se ascende a Cristo, isto é, Cristo é a causa de todo verbo mental corruptível, pois ele é a razão, o verbo incorruptível. Cristo é a própria razão encarnada de todas as razões, porque "o verbo se fez carne" (Cusa, 2003, p. 175).

\section{A Definição que Tudo Define}

De acordo com Nicolau de Cusa, todo conceito humano é "conceito de algo uno" (Cusa, 2008, p. 197), isto é, toda definição que tudo define é não outro que o definido. É a definição que, acima de tudo, nos faz saber. Em outras palavras, “a razão é a definição” (Cusa, 2008, p. 29). O Cusano diz que, talvez, seja Dionísio quem mais se aproximou desse entendimento, quando, ao chegar ao fim da Teologia Mística, afirma que "o criador nem é algo que possa ter nome nem é algo outro” (Cusa, 2008, p. 35). Sendo Deus princípio de todos os nomes assim como das coisas, e ainda que o próprio princípio possa receber muitos nomes, nenhum nome lhe pode ser adequado. Não se podendo constatar que nenhum outro vocábulo dirige melhor a visão humana até o primeiro princípio, é denominado, por isso, "li no-otro" (Cusa, 2008, p. 37). É quando se pode ver que "Deus é não-outro que Deus e que algo é não-outro que algo, e que nada é não-outro que nada, e que não-ente é não outro que não-ente” (Cusa, 2008, p. 39). É quando se vê então que não-outro é a definição que antecede toda definição, sendo, pois, o significado de li o que mais se aproxima do inominável nome de Deus.

Experimenta-se assim que o olhar sensível, sem a luz, nada pode ver, e que a cor não é senão a determinação ou a definição da luz sensível, sendo então que " $a$ luz sensível é o princípio do ser e do conhecer o visível sensível" (Cusa, 2008, p. 43); da mesma forma, o som é o princípio do ser e do conhecer o audível. Suprimido o não-outro, segundo o Cardeal, nada resta da realidade nem do conhecimento. 
Tal conhecimento somente pode ser entendido por meio de si mesmo, não podendo ser expresso de outra maneira. Não pode ser afirmação nem negação, e só pode ser percebido pela coincidência dos opostos, sendo visto "antes de todo acréscimo e de toda supressão" (Cusa, 2008, p. 53), isto é, o não-outro de modo nenhum pode ser alterado ou mudado pelo que quer que seja.

Nessa teoria do conhecimento, que, por assim dizer, desemboca no conceito de não-outro, o não-outro, ele mesmo,

é a razão mais adequada e o discernimento e a medida de tudo o que é, para que seja; e o que não é para que não seja; e o que pode ser para que possa ser; e o que é assim para que assim seja; e o que é movido, para que se mova; e o que está em pé, para que permaneça em pé; e o que vive, para que viva; e o que entende, para que entenda; e do mesmo modo, tudo (Cusa, 2008, p. 59).

É, pois, necessário que o não-outro defina a si mesmo como, da mesma forma, conceituando e nomeando tudo aquilo que pode ser nomeado. Antes do conceito está portanto o não-outro, o que significa que o conceito é "não-outro que conceito" (Cusa, 2008, p. 197). Em consequência disso, o não-outro é denominado de conceito absoluto, o qual pode somente ser visto com a mente, ainda que não possa ser conceituado. O não-outro, não conceituável, no entanto, ao definir-se a si mesmo, se mostra trino. Denominar a trindade como "unidade", "igualdade" e "nexo" é um modo de aceder ao uno, pois são esses os termos nos quais "reluz o não-outro" (Cusa, 2008, p. 65) de modo mais claro. Tratando-se de definições, os termos "isto", "isso" e "o mesmo", segundo o Cusano, "imitam de modo mais brilhante e mais preciso o não-outro" (Cusa, 2008, p. 66, 67), embora sejam termos menos usados. É quando, ao definir-se a si mesmo, o primeiro princípio, significado por meio do não-outro, "nesse movimento definido a partir do não-outro, se origina do não-outro e também a partir do não-outro e é originado o não-outro, no não-outro termina a definição" (Cusa, 2008, p. 67). Qualquer apreensão somente poderá ser intuída para além da capacidade humana, através da contemplação, pois de outro modo não seria possível dizê-la.

Sendo, portanto, outro que o não-outro, Deus "é em tudo, ainda que nada de tudo" (Cusa, 2008, p. 71), o que significa um cessar de tudo que é e que não é, caso cesse o não-outro. A proposta de Nicolau de Cusa é que se veja no inominável não a privação do nome, mas, antes, o "antes de todo nome" (Cusa, 2008, p. 73). É este o modo como o desconhecido reluz no conhecido cognoscitivamente, do mesmo modo que a claridade do sol reluz sensivelmente e que com a visão da mente se alcança por sobre ou fora de toda compreensão.
Tratando-se, porém, do fato de que não se pode explicar nada sem a palavra e só podendo fazê-lo através do termo "ser", deve-se assim proceder para que os que ouvem compreendam. Convém, diz o Cusano, que aquele que especula opere

como o que vê a neve através de um vidro vermelho, o qual vê a neve e atribui a aparência do vermelho não à neve, mas ao vidro; da mesma maneira opera a mente; por meio da forma vê a não-forma (Cusa, 2008, p. 93).

O não-outro é, então, tanto princípio do ser, "através do qual a alma tem o ser, como princípio do conhecer, pelo qual conhece e, como princípio do desejar, pelo qual não somente tem o querer, senão que, especulando seu princípio unitrino naqueles princípios, ascende à sua glória" (Cusa, 2008, p. 95). Pode-se ver então que toda criatura é manifestação do mesmo criador, que se define a si mesmo, ou

da luz que é Deus, que se manifesta a si mesma; como se fosse a exibição da mente que se define a si mesma; que para os presentes se faz pela elocução viva e para os distantes por meio da mensagem ou da escrita (Cusa, 2008, p. 233).

Dialogar é a metáfora mais precisa para designar o projeto filosófico de Nicolau de Cusa. Os nomes impostos pela razão são sempre passíveis de um excedente, de um mais e de um menos, ou seja, de proporção e de comparação e, consequentemente, partem das oposições relativas entre os contrários.

A preferência de Nicolau de Cusa pela teologia negativa ocorre para que possa negar a adequação de todo nome criatural para com Deus e com isso evitar a idolatria, empurrando, por assim dizer, o intelecto no sentido de situá-lo para além da afirmação e da negação, tentando captar formulações "que expressem a captação de Deus como coincidência dos opostos" (Cusa, 2008, p. 251). O Cusano propõe ainda, através da negação e pelo conceito de não-outro, a negação da disjunção comparativa, bem como a negação da própria conjunção. Nega não só que o primeiro princípio seja ou não seja, como se poderia fazer por meio da linguagem intelectual da coincidência, mas chega ao ponto de negar essa mesma linguagem que afirma que o primeiro princípio é e não é. Isso faz com que eleve o intelecto, que é a raiz da razão, e dos termos intelectuais que são a raiz dos racionais, para a busca do primeiro princípio que é anterior à coincidência dos opostos.

Conclui que, nessa teoria do conhecimento, os nomes intelectuais onde os contrários coincidem, são menos inadequados, uma vez que uma linguagem divinal que supere tanto a razão quanto o intelecto pode ser apenas reconhecível, não, porém, praticável. 


\section{Referências}

André, J. M. (2001). Coincidência dos opostos e concórdia: caminhos do pensamento em Nicolau de Cusa. Actas do Congresso Internacional realizado em Coimbra e Salamanca nos dias 5 a 9 de Novembro de 2001, pp. 213 a 243. Separata, Coimbra: Faculdade de Letras.

André, J. M. (2006). Nicolau de Cusa e a força da palavra. Revista filosófica de Coimbra, n. 29, (pp. 03 a 31).

Cusa, N. de (2003). A douta ignorância. (J. M. André, Trad.). Lisboa: Fundação Calouste Gulbenkian. (Original publicado em 1440).

Cusa, N. de. (2008). Acerca de lo no otro, o de la definición que todo define. Introducción, J. M. Machetta y K. Reinhardt, p. 197 (J. M. Machetta, Trad.). Buenos Aires: Editorial Biblos. (Edición bilíngüe)
Fogel, G. (2003). Conhecer é criar. Um ensaio a partir de F. Nietzsche. São Paulo: Editora UNIJUI, Discurso Editorial.

Lyra, S. R. (2012). Nicolau de Cusa: Visão de Deus e teoria do conhecimento. Curitiba: Biblioteca Ichthys.

Vescovini, G. F. (1998). Il pensiero di Nicolau Cusano. Turim: UTET.

Sonia Regina Lyra é Psicóloga - Analista Junguiana, Mestre em Filosofia pela Pontifícia Universidade Católica do Paraná, Doutora em Ciências da Religião pela Pontifícia Universidade Católica de São Paulo e Pós-Doutoranda em Humanidades e Saúde pela Universidade Federal de São Paulo. É Diretora do Ichthys - Instituto de Psicologia e Religião (www.ichthysinstituto.com.br).Email:sonia@ichthysinstituto.com.br

Recebido em 17.05.11

Aceito em 25.03.12 